\title{
Epidemic of fractures during period of snow and ice
}

\author{
Z A RÁLIŠ
}

\begin{abstract}
During four days of snow and ice in which more than $70 \%$ of pavements in the Cardiff area were covered by slippery hard snow and ice the number of patients who attended the accident and emergency department at this hospital with fractured bones increased 2.85 times as compared with those who attended during four control days with comparable hours of sunshine and four control calendar days a year later. Fractures of the arm were increased 3.7 times and of the forearm and wrist $7 \cdot 3$ times. For a town population of one million people who may walk on untreated slippery and icy pavements this means that on average in a single day 74 more people than usual sustain a fracture unnecessarily.

This traumatic epidemic has all the characteristics of a "major accident" and should be treated as such, since mobilisation of additional facilities, staff, and reserves might be necessary. Snow and ice injuries, however, differ from injuries sustained in a major accident in one important point: they may be predicted and prevented. The mass media should warn the population about the oncoming hazards and give practical advice on safer walking on slippery surfaces. The most important aspect of prevention, however, is instant cleaning of pavements around buildings, shops, and houses, especially in town centres and other areas busy with pedestrians.
\end{abstract}

\section{Introduction}

Prevention of injuries plays an important part in modern medicine, particularly in those accidents that have a common and predictable cause and occur on a large scale. Examples of these are injuries and fractures sustained by pedestrians in winter on slippery walking surfaces covered by snow and ice

Department of Accident and Emergency Medicine and Department of Traumatic and Orthopaedic Surgery, Welsh National School of Medicine, Cardiff Royal Infirmary, Cardiff CF2 1SZ

Z A RÁLIŠ, FCCS, MD, senior lecturer in orthopaedics and honorary consultant in an unprepared town. The aim of the present study was to assess the extent of "snow and ice" fractures during a short winter period in the Cardiff area and to draw some practical conclusions.

\section{Patients and methods}

The days of snow and ice chosen, when a dangerous slippery layer of hard snow and ice covered Cardiff pavements and streets, were Sunday 31 December 1978 and Monday 1 January, Tuesday 2 January, Thursday 4 January, and Saturday 6 January 1979. These five days were dominated by a spell of cold weather with periods of heavy snow resulting in fairly thick snow cover over most of southern Wales. In the Cardiff area during the first two days of this spell temperatures were continuously below zero, reaching a minimum of $-8^{\circ} \mathrm{C}$ and a maximum of $-1.5^{\circ} \mathrm{C}$. Brighter weather on 1 and 2 January with 7.5 and 5.4 hours of sunshine led to temporary melting and flattening of the snow on streets and pavements around midday, but subsequent subzero temperatures froze the watery snow again resulting in a continual icy surface. While some of the major roads in the town and surrounding areas were gritted and salted, most streets and especially pavements were left untreated, giving rise to slippery, bumpy, and uneven surfaces dangerous for walking. On each of the five days between 830 and 1030 am 50 pavements were assessed in the Cardiff town centre and adjacent area, and at least 35 of them were found to be completely covered by ice and snow during the first four days and were unwalkable. On the fifth day, Saturday 6 January 1979, the temperature rose (minimum temperature $5^{\circ} \mathrm{C}$ ), the snow and ice started to melt, and only half of the pavements were covered by slippery snow, which was gradually diminishing. For the purpose of this study I considered only the first four days of snow and ice.

I selected as control days two separate groups of days when there was no snow or ice cover in south Wales. I chose four matching days of the week with comparable hours of daylight to the snow and ice days (average daylight seven hours 58 minutes)-namely, Sunday 17 December, Monday 11 December, Tuesday 12 December, and Thursday 7 December 1978; and the same four calendar days as the snow and ice days but a year later-namely, Monday 31 December 1979 and Tuesday 1 January, Wednesday 2 January, and Friday 4 January 1980 . Although these last four days were also generally without any snow or ice, slightly subzero temperatures in the early morning hours of 1 and 2 January 1980 caused some wet pavements in the central town area to be temporarily ice-covered in the early morning. By around 9 30-10 $00 \mathrm{am}$, however, this thin ice had melted.

The records of all 3014 patients who attended the accident and emergency department at this hospital on the snow and ice and 
control days were screened and all clinically diagnosed and radiologically confirmed fractures recorded. The patients with fractures were grouped according to their sex and age-that is, children (0-15 years), young adults (16-30 years), adults (31-60 years), and old people (61 years and over) -and in each group fractures were recorded separately according to the anatomical site of the injury (head, arm, forearm and wrist, hand, spine and chest, and ankle and foot). Injuries to soft tissues, joints (sprains, subluxations, and dislocations), and other parts of the body were not included in this survey.

\section{Results}

Altogether 984 patients attended the accident and emergency department during the four control days with comparable hours of sunlight, 802 during the four control calendar days, and 1021 during the four snow and ice days. Figure 1 shows the distributions of fractures sustained on the snow and ice and control days. The total

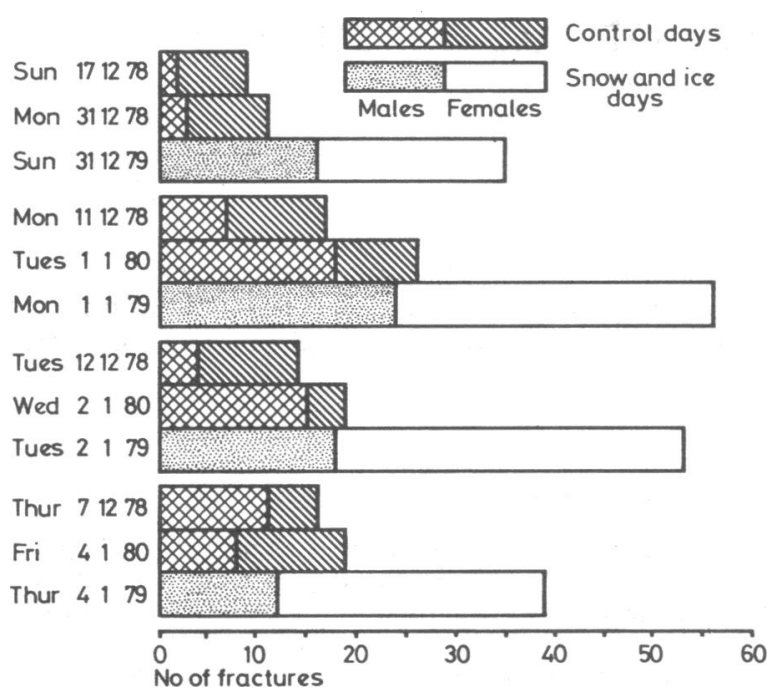

FIG 1-Numbers of fractures sustained on each snow and ice and control day.

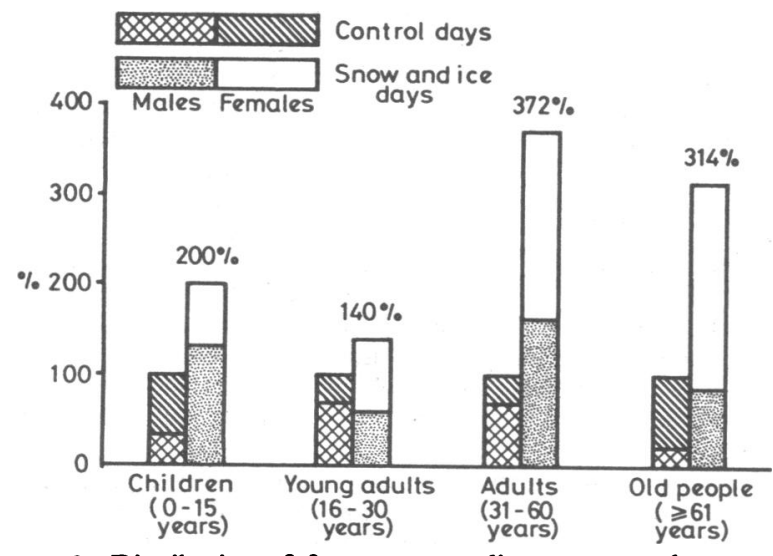

FIG 2-Distribution of fractures according to age and sex on snow and ice and control days.

number of fractures on any day of snow and ice far exceeded the number on control days, with on average 29 more patients than normal presenting at the department, a $2 \cdot 85$-fold increase. Owing to this rise in casualties the average proportion of patients with fractures out of all patients attending the department for the first time more than doubled, reaching $19.9 \%$ as compared with $5.6 \%$ on control days with comparable hours of sunshine and $9.0 \%$ on control calendar days.
The main sufferers during this epidemic were adults and old people, in whom broken bones were more than three times more common than on control days (fig 2). Comparison of the anatomical distribution of fractures on snow and ice and control days (table I) showed a sharp increase on snow and ice days in the number of fractures commonly linked with slipping and landing on the outstretched arm, such as fractures of the forearm and wrist (7.3 times more common) and of the arm (3.7 times more common), and also an increase in fractures often caused by falling completely, such as fractures of the legs, femoral neck, and ankle and foot (3.7, 3.5, and 2.5 times more common respectively). A typical patient during the

TABLE I-Numbers of fractures at different sites sustained on control and snow and ice days

\begin{tabular}{|c|c|c|c|}
\hline Fractures of: & & $\begin{array}{c}\text { Control } \\
\text { days }\end{array}$ & $\begin{array}{l}\text { Snow and } \\
\text { ice days }\end{array}$ \\
\hline 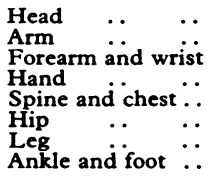 & $\begin{array}{l}\ldots \\
\because \\
\because \\
\cdots \\
\cdots\end{array}$ & $\begin{array}{r}6 \\
10 \\
9 \\
16 \\
4 \\
4 \\
3 \\
11\end{array}$ & $\begin{array}{l}3 \\
37 \\
66 \\
15 \\
7 \\
14 \\
11 \\
28\end{array}$ \\
\hline
\end{tabular}

snow and ice days was an adult with broken forearm or wrist, such patients presenting 16.5 times more commonly than usual; an old person with broken forearm or wrist (risk increased 5.8 times); an adult or old person with a broken arm (risk increased 5.7 and 4 times respectively); an adult with a fractured ankle or foot (risk increased 3.5 times); or an old person with fracture of the femoral neck (risk increased 3.3 times). Simultaneous fractures of the leg and arm occurred in one adult and of the forearm and wrist in two adults and two old people.

\section{Discussion}

The accident and emergency department at this hospital has a turnover of $93000-97000$ patients per year (figures for 1978 and 1979) and is the second biggest casualty department in the country, serving the South Glamorgan catchment area of about 400000 people. It deals with all accidents and emergencies in Cardiff and South Glamorgan. For a realistic assessment of the increase in casualties during the snow and ice days two different groups of control days had to be selected, for two reasons. Firstly, it was important to consider identical days of the week, since the flow of patients attending a casualty department throughout the week follows a definite pattern ${ }^{1}$ (J Ayres, unpublished statistical data for the South Glamorgan AHA, 1979). The matching weekend and weekdays were selected from the first half of December 1978 so that the number of daylight hours would be comparable. Secondly, because of the specific pattern in the movement of pedestrians through the town in the days around New Year it was important to consider identical calendar days without snow cover in the area; these occurred a year later.

Overall the number of fractures sustained during the period of snow and ice was almost three times that sustained during the control periods; the increase in certain specific fractures was particularly dramatic-for example, in adults and old people fractures of the forearm and wrist were 16.5 times more common than normally.

Over four snow and ice days in the relatively small Cardiff community (400 000 people) 118 more patients than usual arrived at the accident and emergency department with broken bones, which means a daily average of an extra 74 patients with fractures per million town population. However shocking these figures may look, the total of all snow and ice injuries was in fact much higher, since a substantial number of people who were treated for bruises, contusions, and joint injuries were excluded from this study. With these the total figure would have been at least double. 
The connection between the high number of unwalkable, slippery pavements and the sharp increase in the number of new patients with fractures is indicated not only by their both occurring at the same time but also by the substantial increase mainly in those fractures that result from slipping and the body landing on the upper extremity, such as fractures of the arm, forearm, and wrist.

Behind the data it is important to see the human suffering and pain incurred, the inconvenience, the working days lost, the extra work for hospital staff, the financial expense, etc. Is it possible, therefore, to predict these epidemic injuries, and what can be done for their efficient management? Is it possible to prevent them?

\section{MANAGEMENT}

Since these injuries are associated with a certain type of winter weather their occurrence is predictable. Their impact will be greater in an unprepared community where subzero temperatures and winters with snow and ice are unusual. Arrival of casualties at hospital on a large scale and during a fairly short period gives this epidemic the character of a "major accident" ${ }_{3}$ or "moderate disaster," 4 and it should be treated as such. Table II compares snow and ice injuries with major accidents. The predictability of these injuries based on weather

TABLE II-Comparison of major accidents and injuries sustained during periods of snow and ice

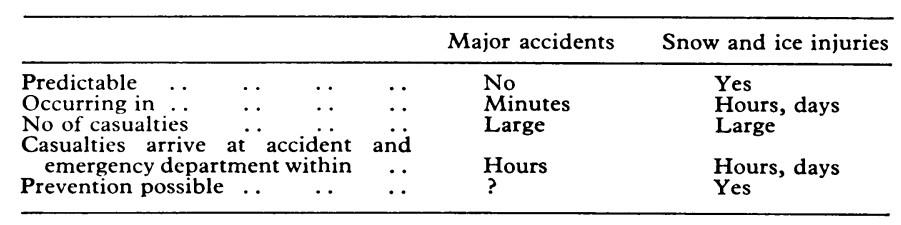

forecasts and regular assessment of local weather and the fact that the arrival of casualties at the accident and emergency department is spread through days rather than hours or minutes make it easier for the health authority to put into operation planned measures and management, and to introduce staff and materials. The casualties represent an increased burden for the ambulance and transport services, police, and administrative staff, and their management requires mobilisation of medical and nursing staff in the departments of accident and emergency surgery, radiology, and anaesthetics and in orthopaedic wards, fracture clinics, and operating theatres. Organisation of local transport and management at hospital level is the most important issue. Unlike in other types of major accident, however, it is not necessary to organise a rescue operation or dispatch a working team to the "disaster site," though many patients would require qualified first aid at the site where they sustained the fracture or injury.

\section{PREVENTION}

To avert a predictable disaster is a matter of common sense. While the authorities do not hesitate to close a bridge, parts of the road, or a pavement that for some reason would be hazardous for traffic and pedestrians, in winter many hundreds of slippery and icy pavements and roads on which a town population has to move are left untreated, creating a real danger for the pedestrian, cyclist, and motorist. This apparently paradoxical approach is caused by the very nature of the winter hazard: the snow and ice comes suddenly, covering roads and pavements within the whole area at the same time. Possible preventive measures may be introduced in two ways: The mass media might give out warnings about danger or existing slippery surfaces, advice to go out only if necessary, and suggestions on how to increase the gripping efficiency of footwear-for example, by using rubber-tread shoes, grips or socks worn over the shoes, or shoe chains (these were recently recommended by the General Post Office's safety department to employees walking outdoors). Really efficient prevention, however, can be expected only from mechanical cleaning and salting of walking surfaces as soon as they become slippery. The question is who should be responsible for this cleaning and who is able to do it. In different parts of the United Kingdom and in countries abroad who have experience of more or less permanent snow cover during the winter two different attitudes prevail.

In some countries, including the United Kingdom, the local authority is responsible for cleaning the footpaths and pavements and carries the liability. In Scotland, for example, this duty is imposed by the Borough Police Scotland Act in most towns. In Canada legislation differs between provinces, but in most the authorities are liable and in cases of injuries on uncleaned pavements may be sued by the citizen. The problem is that, although main roads may be gritted fairly easily in a short time provided a large amount of machinery is available and ready, cleaning pedestrian areas is more difficult; the work cannot be mechanised because pavements are of unequal width, height, and surface and contain various obstacles. Thus most walking areas remain untreated: while the local authorities admit responsibility for snow and ice cleaning, it is simply not in their power to do it efficiently.

For this reason some countries with a long tradition of winters with ice and snow have turned to what is probably the only realistic alternative-that is, that the owners of a building, shop, or house should be responsible for cleaning slippery pavements in front of their property and are held liable for any injury sustained. This system was introduced in some Canadian provinces (for example, Toronto) and in various European countries (for example, Denmark, Czechoslovakia, and Germany), where building and house owners are commonly insured against such events. Naturally, there would be some objections against forcing all householders (including elderly people) to shovel snow, since they themselves would risk injuries and possibly other health hazards, and these factors would have to be considered. Nevertheless, the most effective method of prevention is to introduce compulsory cleaning of pavements in busy town centres and shopping areas with large buildings, offices, and shops where there are enough working staff available and where most pedestrians are moving around. It is beyond the scope of this study, however, to decide the administrative and legal aspects of the problem. I aimed only at drawing attention to the epidemic increase in the number of fractures and injuries in an unprepared town community during a period of snow and ice and the preventability of this potentially disastrous event.

I thank Professor A Ráliš, Mr A Hall, and Miss Irene Boneti for useful information about the legal position in some European countries and Canada; the meteorological office at Cardiff (Rhoose) Airport for valuable information; and Mrs Glenys Stimpson and Mrs Heather Ráliš for preparing and helping with the manuscript.

\section{References}

${ }^{1}$ Karas $\mathrm{S} \mathrm{Jr}$. Patterns in the number of patients seen hourly in a community hospital emergency department. FACEP 1977;6:449-52.

2 Department of Health and Social Services. Health services arrangements for dealing with major accidents. London: HMSO, 1977.

3 South Glamorgan Health Authority. Major accident procedure. Cardiff: South Glamorgan Health Authority, 1978.

4 Rutherford WH, Nelson PG, Weston PAM, Wilson DH. Accident and emergency medicine. Tunbridge Wells: Pitman Medical, 1980.

(Accepted 9 December 1980) 